\title{
Evaluation of Plasma Trace Element and Mineral Status in Children and Adolescents with Phenylketonuria Using Data from Inductively-Coupled-Plasma Atomic Emission and Mass Spectrometric Analysis
}

\author{
I. Knerr ${ }^{a} \quad$ H. Blessing ${ }^{b} \quad$ S. Seyferth ${ }^{d} \quad$ R.J. Watling ${ }^{\text {e }} \quad$ M.A. Chaudhric \\ ${ }^{a}$ National Centre for Inherited Metabolic Disorders, Children's University Hospital, Dublin, Ireland; ${ }^{b}$ Children's and \\ Adolescents' Hospital, ' Institute for Biomaterials, University of Erlangen-Nuremberg and dDepartment of

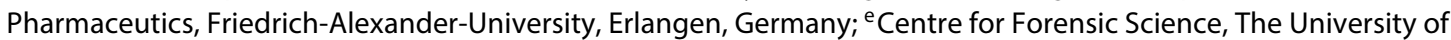 \\ Western Australia, Crawley, W.A., Australia
}

\section{Key Words}

Bio-elements · Diet · Phenylketonuria · Trace elements

\begin{abstract}
Background: Phenylketonuria (PKU) is caused by a severe phenylalanine hydroxylase deficiency; the mainstay of treatment is a low-phenylalanine diet. A diet which is so restrictive is associated with a risk of nutritional deficiencies. We investigated plasma concentrations for 46 elements, including minerals and trace elements. Methods: We enrolled 20 children and adolescents with PKU and 20 matched controls. Multi-elementary quantification was carried out by solutionbased inductively coupled plasma atomic emission spectroscopy (ICP-AES) and ICP mass spectrometry (ICP-MS). Results: With the exception of manganese and aluminium, no significant differences were found for element levels between PKU patients and controls. As a trend, manganese levels were lower in PKU patients than in control subjects $(p<$ 0.05 ) but were within the reference range. There was a positive linear relationship between manganese and tyrosine levels in subjects with PKU $\left(r^{2}=0.2295, p<0.05\right)$. If detectable, potentially toxic elements were only identified in ultratrace quantities in plasma samples of either group; alumini-
\end{abstract}

um levels were found to be slightly higher in PKU subjects than in controls $(p<0.01)$. Conclusion: The combination of ICP-AES and ICP-MS data is a useful diagnostic tool for element quantification at a high analytical rate and for monitoring bio-element status, e.g. in patients on a restrictive diet.

Copyright $\odot 2013$ S. Karger AG, Basel

\section{Introduction}

Phenylketonuria (PKU) is an inborn metabolic disorder in which a profound deficiency of phenylalanine (Phe) hydroxylase enzyme activity leads to an excessive accumulation of Phe in the blood and subsequent neurotoxicity. The estimated frequency of this autosomal recessive disorder in the general population is approximately $1 / 10,000$. $\mathrm{PKU}$ is usually detected in asymptomatic newborns by newborn screening programs. Untreated, PKU causes severe mental disability, microcephaly, epilepsy and other medical and mental health issues. Treatment consists of a strict dietary restriction of natural protein intake, and hence Phe ingestion, along with supplementation of amino acids with manufactured protein substitutes other than Phe. These dietary supplements are enriched with other

\section{KARGER}

E-Mail karger@karger.com

www.karger.com/anm
(C) 2013 S. Karger AG, Basel

0250-6807/13/0632-0168\$38.00/0
Ina Knerr, MD

National Centre for Inherited Metabolic Disorders

Children's University Hospital

Temple Street, Dublin 1 (Ireland)

E-Mail ina.knerr@cuh.ie 
micronutrients, such as vitamins and minerals, to cover daily requirements. Patients with PKU must follow a 'diet for life' to minimise the potentially disabling neuropsychological symptoms of this disorder. The mainstay of treatment is a Phe-restricted diet but novel pharmacological strategies are underway [1]. Essentially, patients who received an early diagnosis and who have adequate dietary treatment and good metabolic control have a good neurological outcome. However, the Phe-restricted diet is a considerable risk factor for nutritional deficiencies and requires close supervision to prevent these. Patients may be at risk of mineral and trace element deficiencies such as zinc $(\mathrm{Zn})$, selenium $(\mathrm{Se})$ or iron $(\mathrm{Fe})[2,3]$. Clinical consequences include anaemia and growth retardation [4]. Acrodermatitis enteropathica-like eruptions have been noted in individuals with various metabolic disorders, including inborn errors of amino acid metabolism [5]. We have also shown that other co-factors in metabolism, such as carnitine, can also be impaired in PKU patients for metabolic or dietary reasons [6]. In addition, oxidative stress is a concern in patients with PKU [7]. The patients' quality of metabolic control, levels of bio-markers such as Phe and compliance depend, in particular, on the dietary regime [8]. Frequent testing of blood Phe levels along with dietary adjustments are essential. Along these lines, a recent Dutch study has revealed that increased self-management, including providing direct online access to blood Phe values, is a safe procedure and is greatly appreciated by PKU patients and their families [9].

While the Phe-restricted diet is clearly effective in avoiding the severe neurological symptoms seen in individuals with untreated PKU, there are ongoing challenges, including compliance in the different age-groups, longterm outcome in adults, risks for pregnant women with PKU, awareness of nutritional deficiencies and also bone pathology [10]. Our group has previously reported distinctive alterations in the metabolic profiles following ingestion of various dietary amino acid mixtures commonly used in the treatment of PKU [11]. We thus proposed to study bio-element status in children and adolescents with PKU, using highly specific ICP-AES and ICP-MS technologies which provide superior sensitivity (down to part per trillion and/or billion levels in solution, respectively).

\section{Methods}

\section{Participants}

We here assess plasma element concentrations in PKU patients on dietary management and in healthy control subjects. All individuals were recruited either from the Metabolic Unit or The Pae- diatric Outpatient Clinic at the Children's Hospital Erlangen/ Germany. The study protocol was approved by the local ethics committee and informed consent and assent were obtained.

We recruited $20 \mathrm{PKU}$ patients ( 9 males and 11 females aged $11.4 \pm 3.4$ years, range $5.9-18.0$ years) and 20 age- and sex-matched controls $(9$ males and 11 females aged $10.9 \pm 3.3$ years, range $5.8-$ 17.5 years).

All patients had been diagnosed following newborn screening. To rule out co-factor tetrahydrobiopterin (BH4) deficiency or $\mathrm{BH} 4$-responsive $\mathrm{PKU}$, all newborns underwent a $\mathrm{BH} 4$ loading test $(20 \mathrm{mg} / \mathrm{kg}$ per day). Patients with blood Phe concentrations $>600$ $\mu \mathrm{mol} / \mathrm{l}$, who had normal urinary pterins and normal blood dihydropteridine reductase activity and were found to be unresponsive to $\mathrm{BH} 4$, were put on a dietary regimen. Further clinical and biochemical details of our cohort have been published previously [6]. A low-Phe diet was carefully adjusted according to individual blood Phe levels; all patients were treated with standard Phe-free protein substitutes enriched with other micronutrients such as vitamins and minerals. Essentially, all patients in this study consumed products provided by the respective various companies or a combination of different formulas. Daily intakes were calculated according to the D-A-CH recommendations on nutrition published by the German (DGE), Austrian (ÖGE) and Swiss (SGE/ SVE) nutritional agencies [12]. The control group consisted of children and adolescents who presented at The Paediatric Outpatient Clinic for minor injuries but who were otherwise healthy.

\section{Procedures}

Blood samples from the patient and control subjects were routinely taken in the mid-morning time frame (9:00 a.m. to noon) at the Metabolic Unit or The Paediatric Outpatient Clinic. Blood samples were obtained in a semi-fasting state from all PKU subjects (on average $4 \mathrm{~h}$ after meals including amino acid supplement, range 1.5-6.5 h). All blood samples for bio-elements were collected in special devices according to manufacturer's instructions (SMonovette ${ }^{\circledR}$ for metal analysis, purchased from Sarstedt, Nümbrecht, Germany); plasma was then extracted and freeze-dried until analysis. In the PKU group, additional serum samples were collected for amino acid analysis (in plastic tubes without anticoagulants) and centrifuged after coagulation at $1,000 \mathrm{~g}$ for $5 \mathrm{~min}$ at room temperature; serum aliquots were stored frozen.

Analysis of serum amino acids in patients with PKU was performed on a standard amino acid analyzer (LC 3000, Eppendorf, Hamburg, Germany) after deproteinisation with 5-sulfosalicylic acid.

Elemental analysis of plasma samples was carried out using a combination of solution-based ICP-AES (Thermo Scientific iCAP 6000) for the determination of $\mathrm{Na}, \mathrm{Mg}, \mathrm{P}, \mathrm{S}, \mathrm{K}, \mathrm{Ca}$ and $\mathrm{Fe}$, and solution-based ICP-MS (Agilent Technologies 7500cs) for the determination of $\mathrm{Al}, \mathrm{B}, \mathrm{Si}$, Ti, Sc, V, Cr, Mn, Co, Ni, Zn, Cu, Ga, Ge, As, Se, Rb, Sr, Y, Zr, Nb, Mo, Cd, In, Sn, Sb, Te, Cs, Ba, La, Ce, Nd, $\mathrm{Hf}, \mathrm{W}, \mathrm{Tl}, \mathrm{Pb}, \mathrm{Bi}$, Th, and $\mathrm{U}$ as reported earlier $[13,14]$. Sample preparation for elemental analysis consisted of dissolving a known mass (accurately weighed to three significant figures in gram mass) of sample in a mixture of high purity (quartz sub-boiling redistilled) nitric acid and hydrogen peroxide $20 \% \mathrm{v} / \mathrm{v}$, in $50 \mathrm{ml}$ volume, acid-washed polyethylene tubes, under individual reflux in a water bath for $24 \mathrm{~h}$. A series of certified reference materials (CRMs), (IAEA-A-13 animal blood; NIST SRM 1547 peach leaves; NIST SRM 1515 apple leaves and NIST SRM 1573a tomato leaves) was 


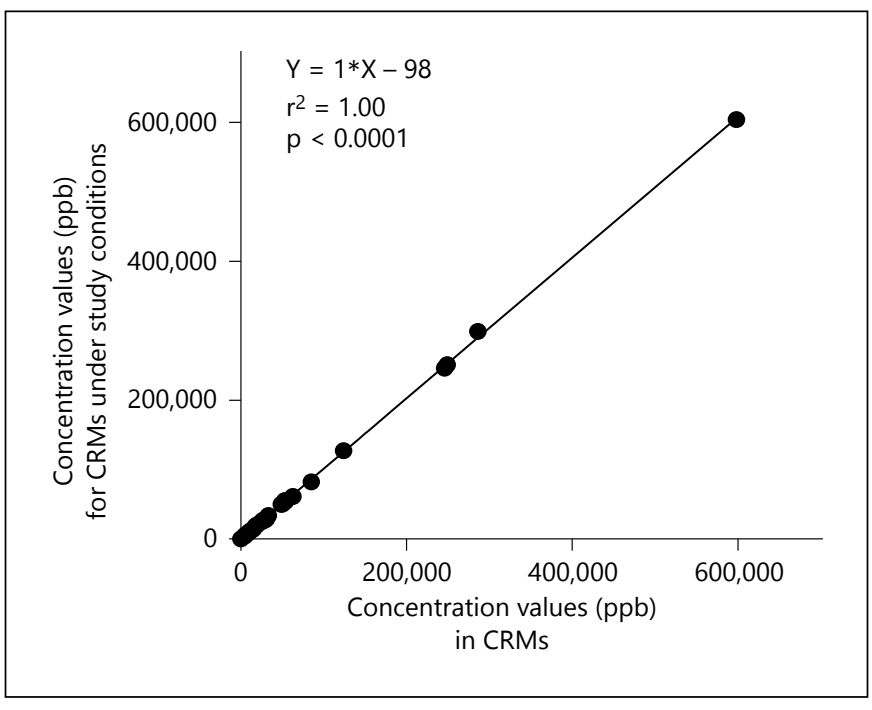

Fig. 1. This diagram shows comparative analytical data for concentration values (ppb) in CRMs and concentration values (ppb) for CRMs obtained under the specific analytical conditions used in this study. Linear regression analysis indicates the accuracy of the data obtained by solution based ICP-MS. Solid line: linear regression line.

dissolved using the same procedure. These standards are certified with reference to NIST (National Institute of Standards and Technology Gaithersburg, Md., USA) reference materials before shipment from the USA. Once dissolution had been achieved, $1 \mathrm{ml}$ of a $40-\mu \mathrm{g} / \mathrm{ml}$ solution of rhodium and iridium was added to each sample and the samples were then made up to approximately $20 \mathrm{~g}$ final mass (accurately weighed to 3 decimal places). The rhodium and iridium preparations were internal standards in the ICP-MS analytical procedure and facilitated any drift correction necessary throughout the analytical run. Internal standards were not used for drift correction in ICP-AES analyses and any drift that occurred via the analytical run was corrected for by reference to a drift correction sample (a bulk matrix-matched sample that was analyzed every five samples) throughout the run. The analytical data for the CRMs were used to determine the accuracy of the sample data; inhouse calibration standards, made by serial dilution of relevant Accutrace ${ }^{\mathrm{TM}}$ Reference Standard single and multi-element solution standards were used to calibrate the instrumentation and provide quantitative data. An indication of the accuracy of the data obtained in this study is given in figure 1 . The dissolution procedure that we used is suitable for all the parameters that we determined, but not for volatile elements such as mercury. The samples were submitted for analysis as a freeze-dried solid and consequently had to be taken into solution prior to analysis. The choice of both dissolution technique and instrumentation used was determined so as to include as many analytes as possible. Very rare elements, such as indium or yttrium, were below the detection limit of the ICP-MS technique [ 0.1 parts per billion ( $\mathrm{ppb}$ ) in the solid sample] and were not included in sample data interpretation. Intra-assay and inter-assay coefficient of variation was $<10 \%$. Element concentrations are given as parts per million (ppm) or ppb as appropriate.

\section{Statistical Analysis}

We used a matched case-control design and sample-size calculation was performed at $80 \%$ power. Data are presented as mean \pm standard deviation (SD). We used a log base-10 scale if applicable. Statistical analysis was performed using the Mann-Whitney U test. Linear regression analysis was used to describe the relationship between two variables. Differences were considered to be significant at $\mathrm{p}<0.05$.

\section{Results}

Using ICP-AES and ICP-MS, we analyzed concentrations of 46 different elements in plasma of children and adolescents with PKU and controls, focussing on nutritional minerals and essential trace elements, but also nonessential elements with potential toxicity.

Analysis of ICP-AES analytical data for plasma levels of essential minerals, such as $\mathrm{Ca}, \mathrm{Mg}$ and iron $(\mathrm{Fe})$, revealed no significant differences between the two groups (fig. 2a). ICP-MS data for plasma levels of essential trace elements, such as $\mathrm{Co}, \mathrm{Cu}, \mathrm{Mn}, \mathrm{Mo}, \mathrm{Se}$, and $\mathrm{Zn}$, were comparable between the 2 groups, with the exception of $\mathrm{Mn}$ (fig. 2b-d). In detail, Mn plasma concentrations were within the reference range for both groups, but significantly lower in PKU patients than in healthy controls $(\mathrm{p}<$ 0.05, fig. 2b).

As a trend, levels of the non-essential trace element $\mathrm{Al}$ were higher in subjects with PKU than in controls ( $\mathrm{p}<$ 0.01 , fig. 2b). In principle, non-essential elements such as lead $(\mathrm{Pb})$ or $\mathrm{Cd}$ were only identified in ultra-trace quantities in plasma samples of either group (fig. $2 c-d$ ).

Dietary recommendations for our patients with PKU regarding consumption of phenylalanine and total protein intake (i.e. natural protein and phenylalanine-free amino acid-based medical formula) are presented in table 1 . We measured serum Phe concentrations ( $404 \pm 236$, range 52-892 $\mu \mathrm{mol} / \mathrm{l})$ and tyrosine concentrations (65 \pm 28 , range $34-145 \mu \mathrm{mol} / \mathrm{l})$ to monitor adherence to diet. We found a positive linear correlation between serum tyrosine and plasma Mn levels in subjects with PKU $\left(\mathrm{r}^{2}=\right.$ 0.2295 , $\mathrm{p}<0.05$, fig. 3). However, there was no obvious relationship between tyrosine and the other bio-elements or between Phe and Mn levels (data not shown).

\section{Discussion}

Dietary restriction of Phe intake with special amino acid supplements is the mainstay of therapy for PKU. Adequate dietary management is important for prevent- 


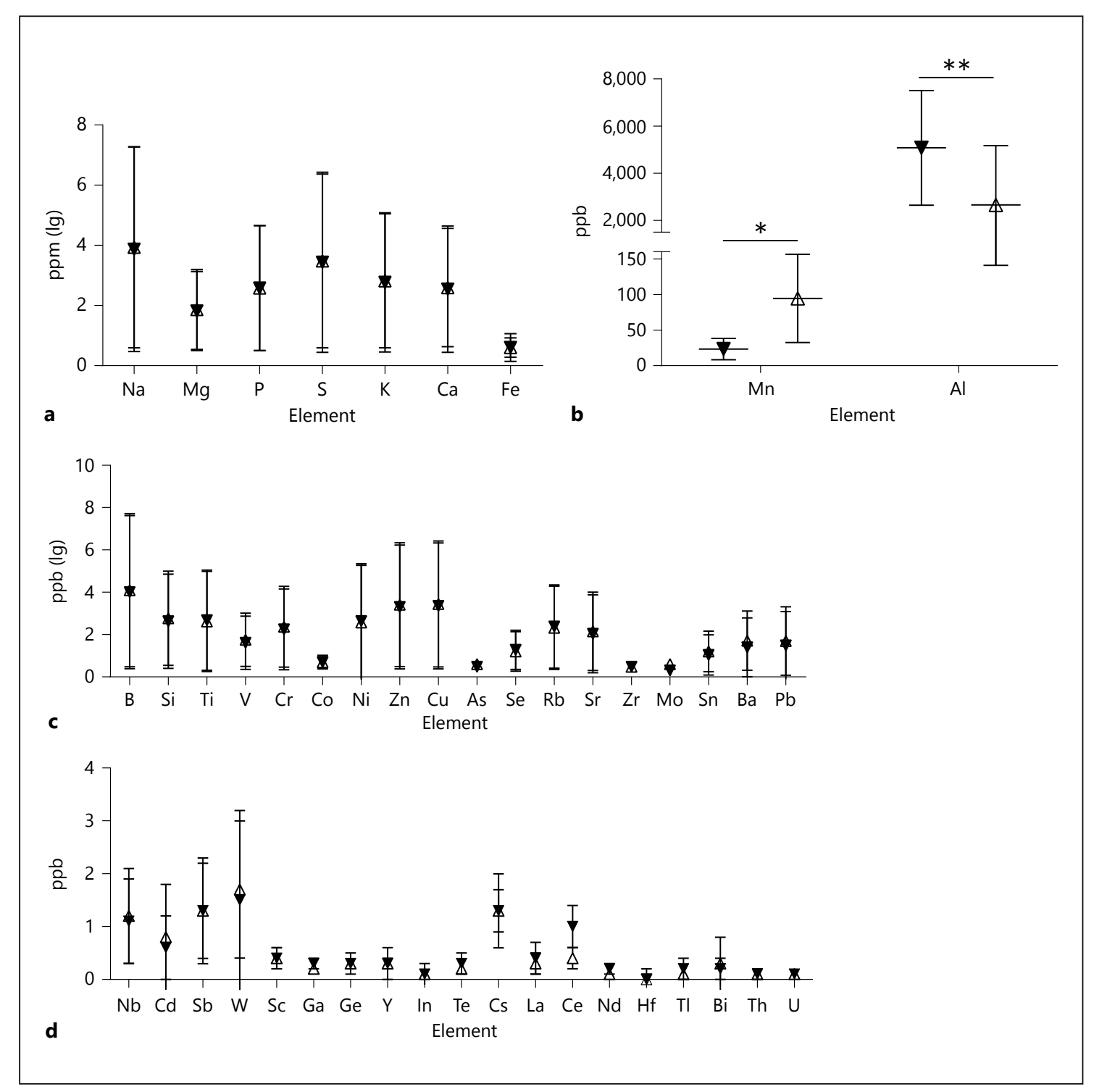

Fig. 2. Plasma data for 46 elements are given as mean \pm SD. Data are presented as log [ppm] for ICP-AES analytical data (a) and ppb or log [ppb] for ICP-MS data (b-d). Data for PKU patients are shown as black triangles $(\nabla)$, data for control subjects are shown as open triangles $(\triangle)$. Differences between groups are not significant except for $\mathrm{Al}$ and $\mathrm{Mn}(\mathbf{b}){ }^{* *} \mathrm{p}<0.01 ;^{*} \mathrm{p}<0.05$.

ing suboptimal nutritional status. Due to the restricted intake of natural protein, the Phe-free formulas provide a high percentage of the daily requirements for micronutrients. The micronutrient content of Phe-free amino-acid based formulas varies considerably. Essentially, all patients had been advised to take their supplements in three divided doses with food to support anabolism.

Apart from $\mathrm{Mn}$ and $\mathrm{Al}$, we did not find any significant differences for element levels between our cohort of patients with PKU and the controls. In particular, elements, such as $\mathrm{Zn}$ and Se, which had been found deficient in phenylketonuric individuals in a previous study [15], were shown to be comparable in the patient and control groups. In this study, the element concentrations (e.g. of $\mathrm{Mn}$ ) were in agreement with published reference values [1618]; as a trend, Mn levels were lower in children with PKU than in controls but still in the reference range. Based on the levels of nutritional trace elements in plasma quantified by multi-elementary ICP-AES/ICP-MS, we assume that dietary intake was adequate for the majority of these 


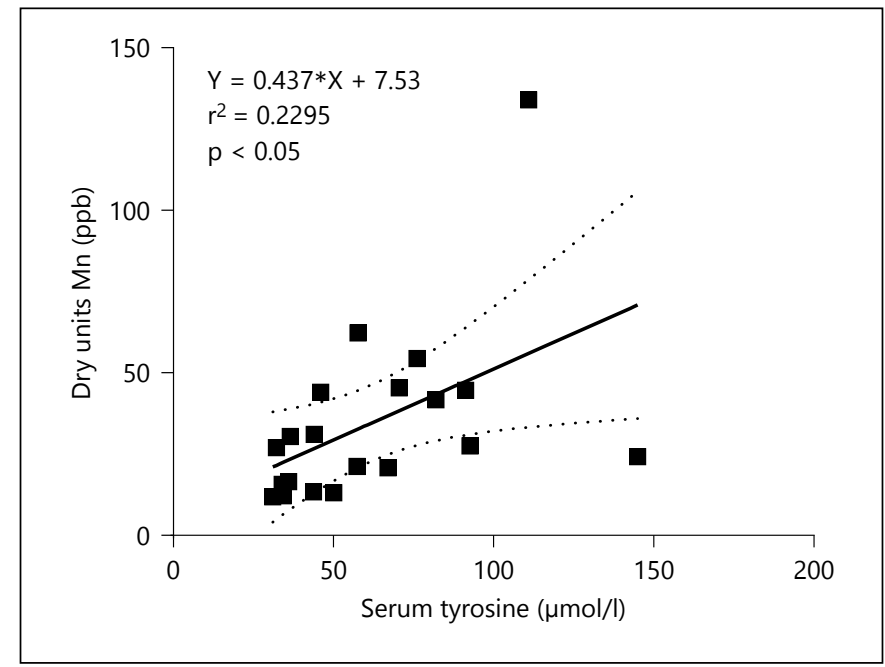

Fig. 3. Linear regression analysis was carried out to estimate the relationship between plasma Mn concentrations and serum tyrosine in children and adolescents with PKU. Solid line: linear regression line, dotted line: $95 \%$ confidence bands of the best-fit line.

Table 1. PKU subjects: dietary treatment, including prescribed dietary phenylalanine restriction and prescribed total protein intake

\begin{tabular}{llrr}
\hline Parameter & \multicolumn{2}{l}{ Descriptives } & \\
\cline { 2 - 4 } & Mean \pm SD & range & $\mathrm{n}$ \\
\hline $\begin{array}{l}\text { Daily Phe intake, mg/day } \\
\quad \text { Age 5-<12 years }\end{array}$ & & & \\
$\quad$ Age 12-18 years & $265 \pm 82$ & $180-400$ & 11 \\
$\begin{array}{l}\text { Daily protein intake, g/kg/day } \\
\quad \text { Age 5-<12 years }\end{array}$ & & & \\
$\quad$ Age 12-18 years & $1.6 \pm 0.3$ & $1.3-2.0$ & 11 \\
& $1.5 \pm 0.5$ & $1.0-2.1$ & 9 \\
\hline
\end{tabular}

bio-elements. However, PKU patients may be at risk for nutritional Mn deficiency, e.g. as a result of inadequate intake of fortified amino acid supplements. This assumption is supported by the linear correlation between plasma $\mathrm{Mn}$ and serum tyrosine concentrations in patients with PKU in our study. Along these lines, there are ongoing questions about the adequacy of this diet for preventing complications, such as sub-optimal growth in childhood [19]. However, physical development in early-treated PKU patients is essentially normal [20]. Previous studies have reported Se and $\mathrm{Zn}$ deficiencies in children and adolescents with PKU [15] but also normal plasma Se and $\mathrm{Zn}$ levels [21]. Reduced antioxidant capacity was described in subjects with PKU, and Se supplements were considered in the light of oxidative stress parameters [22].
Moreover, omega-3 docosahexaenoic acid (DHA) can play a role in alleviating oxidative stress and DHA supplementation has been shown to have health benefits in children with PKU [23]. Optimized dietary strategies, including liquid ready-to-drink protein substitutes, contribute to an improvement of metabolic control and of micronutrient status [8]. In infants with PKU on fortified medical formula, normal trace element levels, including $\mathrm{Mn}$, have been observed [24]. Daily Mn intake in humans noticeably varies with diets, drinking water and supplement use. Daily adequate intake is in the range of $<1 \mathrm{mg}$ for infants to $5 \mathrm{mg}$ for adults [25]. Mn is an essential co-factor of metalloenzymes, particularly mitochondrial superoxide dismutase (MnSOD). MnSOD is a vital antioxidant enzyme which scavenges reactive oxygen species and hence preserves normal cellular functions [26]. Patients with low Mn levels should be carefully advised on how to optimize therapy; follow-up tests and further investigations (e.g. MnSOD enzyme assay) as well as temporary substitution of Mn may also be considered. In this study, Al was found to be higher in PKU patients than in the controls, but the reason for this finding is unclear. It remains speculative as to whether the higher $\mathrm{Al}$ concentrations in PKU subjects may be due to postprandial surges, a higher $\mathrm{Al}$ bioavailability from dietary products, high levels of $\mathrm{Al}$ in PKU foods, contamination, reduced Al clearance or distinctive alteration of mineral metabolism in individuals with PKU. In general, potentially toxic elements, including also $\mathrm{Pb}$ or $\mathrm{Cd}$, were only identified in ultra-trace quantities in the plasma samples of either group, making this not likely to pose specific risks to health in our study cohort.

Taken together, we provide comprehensive data on plasma bio-elements in patients with PKU by using ICPAES/ICP-MS technologies. This method is principally used in medical and forensic science, specifically, toxicology. Compared to other techniques, ICP-AES/ICPMS analysis facilitates sample analysis with greater speed, precision and sensitivity but is more susceptible to contaminants, e.g. from glassware. Our study is the first to apply these technologies in PKU patient plasma samples.

\section{Conclusion}

ICP-AES/ICP-MS technologies were used to investigate plasma concentrations of 46 elements in subjects with PKU and age- and sex-matched controls, focussing on essential trace elements and also on metals with potential 
toxicity. Apart from $\mathrm{Mn}$ and $\mathrm{Al}$, no significant differences for element levels in plasma were found between the 2 groups. However, as a general trend, Mn levels were lower and $\mathrm{Al}$ levels were higher in children with PKU compared to controls, but the clinical significance of this finding is unclear. Ultra-trace quantities of distinctive elements with potential toxicity in both cohorts are very unlikely to pose specific health risks. Based on these multi-elementary ICP-AES/ICP-MS data, we conclude that dietary intake in PKU patients was adequate for the majority of these min- erals and trace elements. However, PKU patients may be at risk for nutritional $\mathrm{Mn}$ deficiency, e.g. as a result of inadequate intake of dietary supplements.

\section{Acknowledgement}

We wish to thank the patients and all other volunteers for their participation in this study. This work was partly supported by an investigator-initiated unrestricted research grant from SHS International (to I.K.).

\section{References}

1 Bélanger-Quintana A, Burlina A, Harding CO, Muntau AC: Up to date knowledge on different treatment strategies for phenylketonuria. Mol Genet Metab 2011;104(suppl):S19-S25.

2 Acosta PB, Yannicelli S, Singh RH, Elsas LJ 2nd, Mofidi S, Steiner RD: Iron status of children with phenylketonuria undergoing nutrition therapy assessed by transferrin receptors. Genet Med 2004;6:96-101.

3 van Bakel MM, Printzen G, Wermuth B, Wiesmann UN: Antioxidant and thyroid hormone status in selenium-deficient phenylketonuric and hyperphenylalaninemic patients. Am J Clin Nutr 2000;72:976-981.

4 Arnold GL, Kirby R, Preston C, Blakely E: Iron and protein sufficiency and red cell indices in phenylketonuria. J Am Coll Nutr 2001; 20:65-70.

5 Tabanlioğlu D, Ersoy-Evans S, Karaduman A: Acrodermatitis enteropathica-like eruption in metabolic disorders: acrodermatitis dysmetabolica is proposed as a better term. Pediatr Dermatol 2009;26:150-154.

6 Weigel C, Kiener C, Meier N, Schmid P, Rauh M, Rascher W, Knerr I: Carnitine status in early-treated children, adolescents and young adults with phenylketonuria on low phenylalanine diets. Ann Nutr Metab 2008;53:91-95.

7 Vargas CR, Wajner M, Sitta A: Oxidative stress in phenylketonuric patients. Mol Genet Metab 2011;104(suppl):S97-S99.

8 Gokmen-Ozel H, MacDonald A, Daly A, Hall K, Ryder L, Chakrapani A: Long-term efficacy of 'ready-to-drink' protein substitute in phenylketonuria. J Hum Nutr Diet 2009;22:422-427.

9 Ten Hoedt AE, Hollak CE, Boelen CC, van der Herberg-van de Wetering NA, Ter Horst NM, Jonkers CF, Wijburg FA, Bosch AM: 'MY $\mathrm{PKU}$ ': increasing self-management in patients with phenylketonuria. A randomized controlled trial. Orphanet J Rare Dis 2011;6:48.

10 Demirkol M, Giżewska M, Giovannini M, Walter J: Follow up of phenylketonuria patients. Mol Genet Metab 2011;104(suppl):S31-S39.
11 Weigel C, Rauh M, Kiener C, Rascher W, Knerr I: Effects of various dietary amino acid preparations for phenylketonuric patients on the metabolic profiles along with postprandial insulin and ghrelin responses. Ann Nutr Metab 2007;51:352-358.

12 D-A-CH-Referenzwerte für die Nährstoffzufuhr, ed 1. Frankfurt, Umschau, 2008.

13 Latkoczy C, Becker S, Dücking M, Günther D, Hoogewerff JA, Almirall JR, Buscaglia J, Dobney A, Koons RD, Montero S, van der Peijl GJ, Stoecklein WR, Trejos T, Watling JR, Zdanowicz VS: Development and evaluation of a standard method for the quantitative determination of elements in float glass samples by LA-ICP-MS. J Forensic Sci 2005;50:13271341.

14 Chaudhri MA, Kemmler W, Harsch I, Watling RJ: Plasma copper and bone mineral density in osteopenia: an indicator of bone mineral density in osteopenic females. Biol Trace Elem Res 2009;129:94-98.

15 Barretto JR, Silva LR, Leite ME, Boa-Sorte N, Pimentel H, Purificação AC, Carvalho G, Fontes MI, Amorim T: Poor zinc and selenium status in phenylketonuric children and adolescents in Brazil. Nutr Res 2008;28:208211.

16 Goullé JP, Mahieu L, Castermant J, Neveu N, Bonneau L, Lainé G, Bouige D, Lacroix C: Metal and metalloid multi-elementary ICPMS validation in whole blood, plasma, urine and hair. Reference values. Forensic Sci Int 2005; 153:39-44.

17 Alimonti A, Bocca B, Mannella E, Petrucci F, Zennaro F, Cotichini R, D'Ippolito C, Agresti A, Caimi S, Forte G: Assessment of reference values for selected elements in a healthy urban population. Ann Ist Super Sanita 2005;41: 181-187.
18 Forrer R, Gautschi K, Lutz H: Simultaneous measurement of the trace elements $\mathrm{Al}, \mathrm{As}, \mathrm{B}$, $\mathrm{Be}, \mathrm{Cd}, \mathrm{Co}, \mathrm{Cu}, \mathrm{Fe}, \mathrm{Li}, \mathrm{Mn}, \mathrm{Mo}, \mathrm{Ni}, \mathrm{Rb}, \mathrm{Se}, \mathrm{Sr}$, and $\mathrm{Zn}$ in human serum and their reference ranges by ICP-MS. Biol Trace Elem Res 2001; 80:77-93.

19 Dokoupil K, Gokmen-Ozel H, Lammardo AM, Motzfeldt K, Robert M, Rocha JC, van Rijn M, Ahring K, Bélanger-Quintana A, Macdonald A: Optimising growth in phenylketonuria: current state of the clinical evidence base. Clin Nutr 2012;31:16-21.

20 Bélanger-Quintana A, Martínez-Pardo M: Physical development in patients with phenylketonuria on dietary treatment: a retrospective study. Mol Genet Metab 2011;104:480-484.

21 Sierra C, Vilaseca MA, Moyano D, Brandi N, Campistol J, Lambruschini N, Cambra FJ, Deulofeu R, Mira A: Antioxidant status in hyperphenylalaninemia. Clin Chim Acta 1998; 276:1-9.

22 Sitta A, Vanzin CS, Biancini GB, Manfredini $\mathrm{V}$, de Oliveira AB, Wayhs CA, Ribas GO, Giugliani L, Schwartz IV, Bohrer D, Garcia SC, Wajner M, Vargas CR: Evidence that L-carnitine and selenium supplementation reduces oxidative stress in phenylketonuric patients. Cell Mol Neurobiol 2011;31:429-436.

23 Koletzko B, BebloS, Demmelmair H, Hanebutt FL: Omega-3 LC-PUFA supply and neurological outcomes in children with phenylketonuria (PKU). J Pediatr Gastroenterol Nutr 2009;48(suppl 1):S2-S7.

24 Acosta PB, Yannicelli S: Plasma micronutrient concentrations in infants undergoing therapy for phenylketonuria. Biol Trace Elem Res 1999;67:75-84.

25 NHMRC Nutrient reference values, 2005. http://www.nrv.gov.au/nutrients/manganese. htm (accessed 10/01/2013).

26 Holley AK, Dhar SK, St Clair DK: Manganese superoxide dismutase versus p53: the mitochondrial center. Ann NY Acad Sci 2010; 1201:72-78. 